characterizing each local (Oxfordshire) stratum have been collected from the beds in sitú. Lists of fossils are given.

4. "The Causes of Variegation in Keuper Marl and in other Calcareous Rocks." By Gerald Tattersall Moody, D.Sc., F.C.S. (Communicated by Professor W. W. Watts, M.A., F.R.S., Sec.G.S.)

Analyses of a large number of specimens of Keuper Marl bring to light the fact that the red portion of a variegated rock contains a considerably higher percentage of iron and lower percentages of calcium-carbonate and magnesium-carbonate than the green portion. This is in agreement with earlier observations that red strata are usually less calcareous than adjacent green strata; but the author is unable to confirm the hypothesis advanced by Maw, that the lighter-coloured bands in variegated rocks are produced by bleaching or discoloration of red rocks through addition from extraneous sources of lime and magnesia. On the contrary, it is found that the removal of iron existing as ferric oxide from a homogeneous rock-mass is inhibited if calcium-carbonate, or magnesium-carbonate, or both of these substances be present. When, however, a chalybeate water (ferrous bicarbonate solution) permeates a rock containing magnesium-carbonate or calcium-carbonate, iron is precipitated as ferrous carbonate, and an equivalent weight of magnesium or calcium passes into solution. Subsequent access of air oxidizes the ferrous carbonate, and red or yellow ferric oxide is produced. The author finds that when a green marl is subjected to the action of chalybeate water in the manner indicated, it is readily converted into a material closely approximating, both in appearance and in composition, to the natural red marl of the same rock-mass.

The author concludes that the variegation of the Keuper Marls and of other calcareous rocks has been brought about by the percolation of chalybeate water through the light-coloured mass, the more porons parts of which have in consequence become stained with ferric oxide, while the harder and more crystalline parts, being non-porous, have remained unchanged. The uniformity in distribution of ferric oxide in sone red rocks, such as the New Red Sandstone, suggests that the iron contained in them has probably been derived from cbalybeate water in a similar manner.

The next Meeting of the Society will be held on Wednesday, November 8 th, 1905.

CORRESPONDENCE.

\title{
WHERE ARE THE TYPES?
}

Sir,-May I ask if any of your readers can kindly give me the information as to where may be found the types of S. P. Pratt (Kelloway Ammonites from Christian Malford) and of Young \& Bird (Lias . Fossils in "Geology of Yorkshire") ? The information is required for the purposes of the Palaontologia Universalis.

Westfield, Thame, Oxon.

S. S. Buckman.

1 Quart. Journ. Geol. Soc., vol. xxiv (1868), pp. 35 et seqq. 

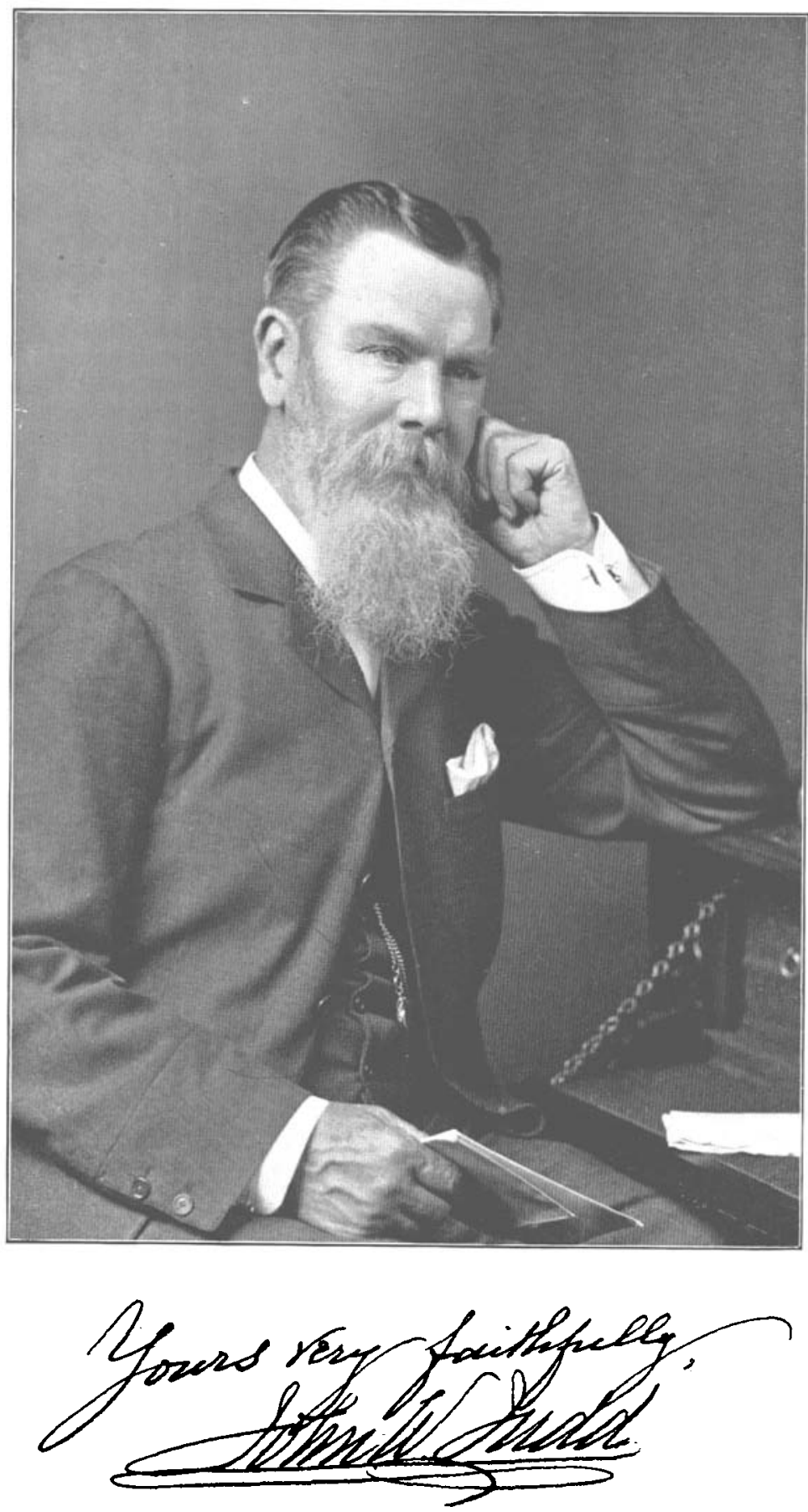

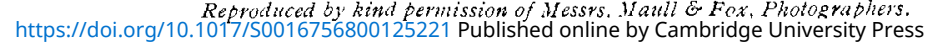

